\title{
CONSIDERACIONES EN TORNO A LA SENSIBILIDAD GAY EN LA NARRATIVA DE \\ REINALDO ARENAS
}

\section{David William Foster ${ }^{*}$}

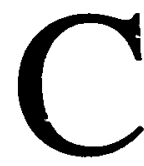

oncluyamos desde el principio: yo no pretendo proponer una definición categórica de una llamada sensibilidad gay, ni tampoco pretendo rastrear las implicancias de tal sensibilidad para una caracterización de la narrativa de Reinaldo Arenas. Más bien, lo que quisiera aqui ensayar, partiendo da algunas constelaciones temáticas y algunas prácticas discursivas en Arenas, y tomando en consideratión hechos nucleares de su vida, en particular la terrible, desgarradora ironía de los últimos años de su vida en Nueva York que lo llevaron al suicidio, es un prolegómeno en torno a las consideraciones ideológicas que se plantean en una aproximación a la dimensión homosexual de un escritor y su creación estética.

Para la persecución de esta cuestión, quicro acordarme de la proposición que pone Cela al comienzo de su novela Mrs. Caldwell habla con su hijo (1953), donde dice que "novela es todo aquello que, editado en forma de libro, admite debajo el título, y entre paréntesis, la palabra novela"

Arizona State University 
(9). También quiero acordarme de algunas de las apreciaciones de Manuel Puig en una entrevista última que sostuvo con una publicación argentina, del tenor de que los homosexuales no existen, siendo ellos una creación de la burguesía hegemónica como una movida clínica para circunscribir, para deslegitimizar ciertas conductas eróticas (es cierto que tales apreciaciones dan una resonancia latinoamericana a consideraciones formuladas a lo largo de muchos escritos sobre el tema de Michel Foucault y no se extienden apreciablemente mucho más allá de lo que propuso Gore Vidal en el posfacio a la segunda edición de The City and the Pillar (1948), novela abresurcos de la nueva conciencia de posguerra en USA, donde el autor afirma que no hay homosexuales, sino tan sólo actos homoeróticos en los que participan individuos cuya autoconciencia e identidad será o no será la de un "homosexual" y que intervendrán o no intervendrán en otras conjugaciones corporales que podrán o no prodrán llamarse heterosexuales.

Dicho que hubo lo anterior, postulamos una primera hipótesis de trabajo: un tex to homosexual, o, por ser más preciso, un texto de sensibilidad gay sería en primera instancia cualquier texto que se identifica como tal, como por ejemplo Utopía gay (1983) del mexicano José Rafael Calva. Visto desde esta propuesta, no puede tratarse de someter el texto a una regla de medición, a colocarlo en la balanza del "avoir du poids" conceptual para ver si cumple o no cumple con la tabla periódica de las definiciones genéricas. De por si, el texto que se postula de tal naturaleza gana el derecho, por el mero atrevimiento del gesto de autodenominación, de convertirse en una fuente de conocimiento de un fenómeno así enmarcado, con lo cual no quiero decir que semejante gesto en si le presta inapelable autoridad al discurso. Más bien, se trata de dar valor al trabajo de elaboracion de un texto desde una determinada perspectiva conceptual, para centrarse en la proposición emitida como toma de posición desde la cual se puede indagar en el discurso que asi autorreflexivamente se monta, confirmando o rechazando la coherencia que la auscultación crítica (aún cuando ésta trate de la simple lectura ociosa) sea capaz de descubrirle.

Sin embargo, huelga decir que pocos son los textos de nuestra nutrida tradición literaria que manifiestan el atrevimiento de llamarse homosexuales, directa o metafóricamente. William S. Burroughs llamará a una de sus primeras novelas Queer y Larry Kramer una de las suyas Faggots, pero si hoy está fuera de cuestión un planteo de la homosexualidad en obras decimonónicas como The Picture of Dorian Gron de Oscar Wilde, Dr. Jekell and Mr. Hyde de Robert Louis Stevenson, The Leaves of Grass de Walt Whitman, Billy Budd de Herman Melville y The Bostonians de Henry James, 
se trata más bien de una óptica crítica "entendida" que ha sabido recoger de los textos semas, lugares comunes, alusiones y tropos confirmados por la literatura explícita pero clandestina del submundo gay del diecinueve, y no de la autocaracterización de los textos, cosa por demás imposible dentro de la ideología social dominante de la época (aunque la atrevida explicitez de fragmentos claves de Whitman ha quitado el sucño a más de una generación de profesores de la literatura norteamericana, para los que las palinodes del Whitman anciano no dejan de sonar a poco convincentes).

De ahí que se insinúe una segunda propuesta: nuestra aproximación a un texto como perteneciente al dominio de la escritura gay se fundamenta en aquellos trazos del texto que, dentro de una métrica de legitimidad interpretativa, se postule implícitamente tensado en la consideración de un segmento de un panorama de cuestiones gay. Desde la perspectiva de esta postulación, no urge que un texto tal se centre exclusivamente en una temática homosexual, ni que el personaje central manifieste la "problemática" de la identidad gay: precisamente, para cierta conciencia homofóbica, un texto homosexual no es ni nada más ni nada menos que uno de todos aquellos que enfocan la "trágica maldición" de las perversiones contra natura, vista como una "problemática" para un individuo que se entrega al aniquilamiento provocado por su indecente "condición". Visto el asunto desde el planteo de Puig/Foucault/Vidal, el error de mala fe de dicha conciencia radica en la falsedad de pensar a los individuos como susceptibles de ser perfilados exclusivamente en términos de una presunta sexualidad rectora e indivisible $y$ la misma consideración se haría extensiva a una identidad configurada tan solo en términos de una afiliación partidaria, una profesión religiosa o una vivencia étnico-racial).

La estrategia hermenéutica que se deriva de esta postura se valdrá de aglomeraciones temáticas y discursivas que se puedan identificar en los textos, para proponer la presencia de una elaboración textual que se pudiera llamar homosexual o gay. En el caso de Arenas, en un escrito como Arturo, la estrella más brillante (1984), no hace falta que el texto se autodenomine gay para que el lector perciba que el argumento parte de la condición homosexual de Arturo y que los vaivenes de su existencia, hasta la fuga que resulta al final suicida en la balacera que lo mata, tienen que ver con las consecuencias de la conducta impropia por la cual Arturo queda confinado en un campo de concentración.

El hecho de que se trate de una desviación atribuida - de una interpretación de una manera de ser impuesta - por la policía y, luego, de un sistema de cínica explotación sexual donde la homosexualidad atribuida es 
confirmada por el uso homoerótico que los machos celadores hacen del cuerpo de los internados, solo sirve para confirmar la distancia que media entre una esencia homosexual que escamotean escritores como un Arenas o un Puig, y el cuestionamiento de una conducta que es el resultado de la imposición de una interpretación hegemónica del individuo, operación represiva/opresiva que proviene igualmente de la derecha burguesa y de la izquierda estalinista. Lo fascinante de un tex to como Anuro, la estrella más brillante (o de El lugar sin límites [1966] de José Donoso) no es el retrato de "un homosexual", sino la configuración en un individuo del impacto de las estructuras del poder sexual que crea al homosexual como una identidad impuesta y no como una conducta de elección personal (es decir, en otros términos, cómo coja el individuo carece absolutamente de importancia, dándose por descontado que se vale de su cuerpo como corresponde a un maricón). De esta manera, la narración se centra en última instancia menos en la identidad que ha forjado el individuo (hipótesis de rancia ingenuidad burguesa, por lo que implica del individuo exento de los procesos formativos fuera de su control y de los que ni tiene conciencia), para dilatarse respecto a la codificación de ciertos individuos como cumpliendo en la dinámica social un papel asignado por la fuerza al maricón.

Aún más interesantes son las referencias a un comportamiento homoerótico en El palacio de las blanquisimas mofetas (1980), a una marginación y subsiguiente violación autoritaria del cuerpo en $E l$ mundo alucinante (1969) y a una dinámica interpersonal de repudio moral en Vieja Rosa (novela con la cual Arturo forma una secuela): en ningún caso se trata de un protagonista identificable como "homosexual", gracias a la operación clasificatoria de una ideología social que se conforma con ponerle etiqueta a la gente, para asi disponer mejor de un mundo ordenado, en el cual hasta los marginados cumplen con una función en la dinámica del poder organizador. Con lo cual no se quiere negar que la conducta homoerótica está presente en estas novelas, e inclusive como una "jouissance" que se contrapone a la omnipresente muerte de una sociedad que está atravesando una irrefrenable decadencia social y moral.

En Palacio, al que se puede tildar de ser una de las novelas más feroces de la literatura latinoamericana contemporánea (por la imagen sin concesiones que artoja sobre la hipocresía de la sedicente decencia pequeñoburguesa), el narrador se erige en ojo avizor implacable, sin concesiones, del derrumbe de una familia cubana ejemplar. En este reino de la disfunción afectiva, la cvolución de una conciencia de los placeres ilegítimos del cuerpo sirve de baluarte contra la disolución definitiva de un personaje lacerado una 
y otra vez por las hipocresias de la decencia dominante. Repitámoslo: no se trata en absoluto de la "problemática" de un homosexual, sino de una conducta personal que involucra una gama de actos eróticos de índole homoerótica. La resonancia de estos actos, la manera de que lo colocan al individuo fuera de la ley en sus múltiples versiones autoritarias, funciona para definir contestatariamente los parámetros de una conciencia frente a la sociedad, cuya hipocresía y cuyo desmembramiento violento del individuo quedan especificados por una conducta homoerótica que deriva lo mismo de una marginación asumida por el individuo como de una identidad que se le impone porque la dinámica social necesita, en un proceso de diferencia semiológica, de una categoría de sexual outlaws, para poder mejor jactarse de su decencia autosuficientc.

Tercera propuesta: Ante la condición del homosexual como entidad formulada por la dinámica social, en una alevosa distribución de los papeles en el drama coletivo, se puede hablar de la construcción de una identidad homosexual, no en los términos de un libre albedrío psicológico que reduplica la moral burguesa del ser humano como free agent trascendiendo el habla del código social, sino como un constructo que se elabora dentro de y en oposición a los patrones de las excluyentes definiciones del patriarcado hegemónico. Asumir las etiquetas degradantes de la moral contundente $y$, en un gesto de tropismo retórico, proveerles de un nuevo significado de dignificación humana, es participar en la construcción de un campo semántico a contrapelo de las estructuras dominantes. El hecho de que este campo se configure coo esencialmente (homo)sexual, no quiere decir que se esté replegando ante las categorías de la interpretación social dominante: el queer de la novela de Burroughs, el faggot de la novela de Kramer, no son seres que se visten pasivamente de los rótulos de los dueños del poder sexual. Más bien, los términos de humillación personal se resemantizan como consignas de una reformulada conciencia de conducta personal que se sustrae, de un saque, del dominio de la represión erótica. El resultado es, si no una trascendencia de las estructuras del poder sexual (dado el hecho de que nadie puede optar por sustraerse de la historia, salvo suicidandose...), una confrontación estratégica con dichas estructuras en aras de un proyecto de reformulación de la codificación social de la (homo)sexualidad.

Para el lector que interioriza inconscientemente la hegemonía antisexual/homofóbica o asume conscientemente su defensa armada (y aquí no se está hablando en términos preponderantemente metafóricos), la escritura asi centrada se convierte en un reto, para que el proceso de descodificación interpretativa luche contra ella o para que la vaya asumiendo 
como una legítima configuración semiológica de la realidad social y del manejo personal del cuerpo dentro de la misma. De ahí que el narrador, en un gesto desgarrador que lo aleja definitivamente del mundo social en el que está inscripto por las circunstancias de su nacimiento, se conciba, partiendo de su autoatribución como ojo escrutador, como un traidor de todo cuanto fisgonea:

Está en el patio. Es de noche. Los demás duermen. La luz empalidece Jas cosas, las piedras, el fondo de las latas, sus manos. $Y$ aquello llega, $y$ aquello acosa, y lo hace superior, fuerte, solo, terriblemente desgraciado. Está en el campo. Es un muchacho. Desde la arboleda se oyen las voces de los familiares que hablan en el patio mientras deshojan el maíz. Son voces conocidas que forman la conversación corriente de todas las tardes. Pero hay algo detrás, hay algo detrás de aquellas palabras que sólo él comprende; y cada palabra, cada sonido se van convirtiendo en un reto, en un terror, en una posibilidad de temura, en un enigma, su enigma, que solo a él le está pernnitido descifrar. Pero ¿qué se debe hacer?, a quién debe acudir si es que alguien en este caso puede orientarlo. Está en el comedor de la casa, en el pucblo. De la radio sale una canción popular, una canción estúpida, corriente, de esas que tanto le gustan a su prima Esther. Y también allí hay algo que lo obliga, que lo conmina, que lo transporta, que lo eleva, que lo deja solo con miles de interrogaciones distintas a las que la vida cotidiana, práctica impone... Ahora ya es el condenado, ya es el elegido, el que no pucde conformarse; el dueño de un espanto que no se ajusta a los estrechos límites de las desdichas diarias. El que no puede oír una canción y decir, oigo una canción, y es todo. El que no puede oir una conversación familiar y decir, conversan, y es todo. El que no puede al atardecer caminar, sencillamente por las calles, disfrutar un instante de esa frescura, como hacen los demás, y decir, eso es todo, sin ir más allá, sin investigar lo que no se ve, sin hacer preguntas que, en última instancia, sólo a él le interesarian las respuestas...Ahora comprendia que era justificada la desconfianza que los otros tenian para con él. Pues ¿qué era él para ellos sino un traidor, alguien que se consideraba (que se sabia) más alla, alguien que vigilaba para burlarse, alguien que no tomaba en serio lo que para ellos justificaba la existencia, sino lo otro, lo que nadie veía, lo intítil? Era un traidor. Y, de seguir viviendo, no le quedaba otra alternativa que ser siempre el rechazado. (160-161).

Cuarta y última hipótesis: La sociedad que se erige en defensa de una norma antierótica/homofóbica puede tolerar una literatura homosexual si cumple con dos criterios: ser abierta y declaradamente homosexual en la temática, llamar a las cosas por su nombre, lo cual implica, por supuesto, 
que hay nombres fijos con los que se les puede poner etiquetas a las cosas, a los seres humanos reificados en las casillas de las abstracciones fenomenológicas del código hegemónico. Y en segundo lugar, entregar a los personajes de dichos textos a los verdugos de ese código, empaquetarlos como chivos expiatorios cuyo violento fin, ya sea espiritual o físico, sirve para confirmar la estabilidad social, la rectitud moral, la sedicente higiene del cuerpo burgués. Arturo es un texto conmovedor no solamente porque en el cuerpo del protagonesta se dan cita todos los mecanismos de la persecución del individuo por el poder ciego y arbitrario del estado, sino también porque Arenas pautiza sin concesiones cómo una vertiente del estado castrista reduplica el cinismo del código moral de la sociedad burguesa que habia pretendido revolucionar.

Sin embargo, desde otra mirada crítica, Arturo no puede dejar de reiterar la figura del patético maricón, víctima de su naturaleza endeble y violentado por una sociedad que sus neurosis le impiden encarar sanamente (v.gr., con el risueño machismo del protagonista de La Habana para un infante difunto [1979] de Guillermo Cabrera Infante, cuya llana y simpática picardía erótica le permite desafiar holgadamente la misma moral pacota que aniquila a Arturo).

Pero al llegar a una novela como El palacio de las blanquísimas mofetas, el lector se halla ante un texto cuyo tenor, aparte de la implacable y aplastante visión grotesca que arroja de la sociedad cubana/latinoamericana, se configura como una resistencia a brazo partido contra el encasillamiento temático, estilístico, discursivo. Amén de su condición como parangón de una textualidad narrativa totalmente contingente y metonimica, una fuga delirante que atraviesa cl espacio, el tiempo y las mentalidades de los personajes (como la Muerte en bicicleta desbocada que constituye el leitmotif del texto y la imagen prefigurativa de la tapa de la primera edición venezolana), Palacio se propone la desarticulación total de las estructuras del conocimiento burgués del mundo que describe, en lo que más que cualquier consideración de índole temática, constituye el meollo de una sensibilidad gay. Como lo gay no puede ser una cuestión de una cerrada clasificación psicosexual que congela al individuo en su posición dentro de la red del código dominante, más que nada se vuelve una manera de contemplar la organización social en términos de una contingencia radical que hace reventar una vez por todas la cárcel del lenguaje histórico: "Pero si algo permanecía fijo en él era la condición fatal, inexplicable - entonces - de encargado de administrar los gritos" (159). 
Enfocado el asunto desde esta perspectiva, mucho más que Arturo (novela que he analizado en otro estudio sobre temas gay y lesbianos en América Latina), Palacio será el texto más gay de un escritor que terminó entregando su vida como última consecuencia de una conducta vital en la que se fundamentaba honradamente para asumir ser él que administraba los gritos: "Viejos desgraciados, lo que nunca les perdonaré no es que me hayan traido a este mundo, sino que me hayan obligado a quedarme en él" (39).

\section{RESUMO}

A partir de algumas constelações temáticas e de algumas práticas discursivas encontradas na obra de Reinaldo Arenas, o antigo é um prolegòmeno a algumas consideraçōes de ordem ideológica que se colocam quando de uma aproximação à dimensão homosexual de um escritor e sua criação estética.

\section{REFERÊNCIAS BIBLIOGRÁFICAS}

ARENAS, Reinaldo. El palacio de las blanquisimas mofetas. Caracas: Monte Avila, 1980.

BRONSKI, Michael. Culture Clash: the Making of Gay Sensibility. Boston: South End Press, 1984.

CELA, Camilo José. Mrs. Caldwell habla con su hijo. 2. ed. Barcelona: Destino, 1958.

FOSTER, David William. Gay and Lesbian Themes en Latin American Writing. Austin: University of Texas Press, 1991.

GREENBERG, David F. The Construction of Homosexuality. Chicago: University Press, 1988. JAY, Karla. Lavender Culture. New York: Jove Publications, 1979.

LESBIAN texts and contexzs: radical revisions. Edited by Karla Jay and Joanne Glasgow. New York: New York University Press, 1990.

MONSIVÁIS, Carlos. Escenas de pudor y liviandad. 9a ed. México, D.F.: Editorial Grijalbo, 1988.

PUIG, Manuel. "El error gay". El porteño, septiembre 1990-, págs. 32-33.

SEDGWICK, Eve Kosofsky. Epistemology of the Closet. Berkeley: University of Califomia Press. 1991.

VIDAL, Gore. The Cin and the Pillar Revised. New York: E. P. Dutton, 1965.

YINGLING. Thomas E Hart Crane and the Homosexual Text: New Thresholds, New Anatomies. Chicago: University of Chicago Press, 1990. 